Research Article

\title{
The Influence of Soil Disintegration in Water on Slope Instability and Failure
}

\author{
Yongzheng Qi $\mathbb{D}^{1},{ }^{1}$ Yunfei Guan $\mathbb{D D}^{2}{ }^{2}$ Liyan Wang, ${ }^{1}$ Pengming Jiang, ${ }^{1}$ and Guofu Zhang ${ }^{1}$ \\ ${ }^{1}$ School of Civil Engineering and Architecture, Jiangsu University of Science and Technology, No. 2 Mengxi Road, \\ Zhenjiang 212003, China \\ ${ }^{2}$ Geotechnical Engineering Department, Nanjing Hydraulic Research Institute, Nanjing 210029, China \\ Correspondence should be addressed to Yunfei Guan; yfguan@nhri.cn
}

Received 14 May 2020; Revised 24 July 2020; Accepted 24 August 2020; Published 2 September 2020

Academic Editor: Qiang Tang

Copyright (c) 2020 Yongzheng Qi et al. This is an open access article distributed under the Creative Commons Attribution License, which permits unrestricted use, distribution, and reproduction in any medium, provided the original work is properly cited.

The instability of the bank slope of the reservoir will cause great loss to the life and property of the people in the reservoir area. The landslide of the reservoir not only occurs in the period of water level plummeting, but also occurs in the period of water level rising. In this paper, the mechanism of slope landslide in the rising stage of water level was studied from the perspective of soil disintegration in water. A series of tests on the disintegration of prisms and cylinders with the same volume and different bottom side lengths (diameter) were carried out. The results show that the specific surface area of the same volume sample was different, and the disintegration behavior was different. The larger the specific surface area of the same shape sample was, the faster the disintegration speed was. The deeper the water depth was, the shorter the disintegration time was under the same initial conditions. It shows that when the water level of the reservoir rose, the deeper the water depth was, the greater the pore osmotic pressure was, and the more the soil mass of the slope collapsed. This led to the reduction of the pressure on the lower part of the slope, the decrease of the antisliding force of the soil, and the failure of the slope.

\section{Introduction}

The instability of the bank slope of the reservoir will cause great loss to the life and property of the people in the reservoir area. The water level of the Vaiont reservoir in Italy with a total storage capacity of 170 million $\mathrm{m}^{3}$ rose $120 \mathrm{~min}$ in 30 days, which led to the catastrophic overall landslide. The volume of landslide mass was up to 240 million $\mathrm{m}^{3}$. Six towns in the lower reaches of the river were destroyed by the surging waves causing thousands of deaths [1]. According to investigation, $49 \%$ of the landslides near the Roosevelt lake occurred in the early stage of water storage, $30 \%$ occurred in the period of $10-20 \mathrm{~m}$ sudden drop in water level, and the rest occurred in other small landslides. In Japan, approximately $60 \%$ of Reservoir Landslides occurred in the period of sudden drop of reservoir water level and $40 \%$ in the period of rising water level, including initial impoundment [2]. After the completion of the Three Gorges project, there are more than 1190 landslides, large and small, in the range affected by the water level of $175 \mathrm{~m}$ reservoir [3]. Therefore, the instability of the reservoir bank slope may occur not only in the period of water level sudden drop, but also in the period of water level rise. Liu pointed out that the effect of water level rise on slope instability and failure was mainly reflected in the effect of pore water pressure and the weakening of strength parameters of immersed sliding surface [4]. The stability coefficient of landslide decreased with the increase of water level fall speed when the water level fell [5]. The faster the water level rose, the higher the slope stability coefficient was [6]. The mechanism of slope stability under different water level rise and fall rates studied by Ru-Xue et al. showed that when the water level dropped, the water pressure outside the slope decreased rapidly, while the water pressure inside the slope decreased relatively slowly, and the increased sliding force of the slope led to the instability of the embankment slope with forming the pressure difference from the inside to the outside of the slope [7]. Han et al. showed that the higher the slope height, the more obvious the lag effect of pore water pressure and matrix suction [8]. Liu showed that the 
curve between relative permeability coefficient and matrix suction of unsaturated soil has a great correlation with the location of saturation surface and safety coefficient of reservoir bank slope [9]. Xu and Jian showed that the larger the permeability coefficient of soil, the deeper the soil moisture spread distance, and the faster the speed [10]. To sum up, water is an important factor affecting the stability of the slope. The landslide caused by the reservoir includes the landslide caused by the rise of water level in the early stage of water storage and the sudden drop of water level. It is generally believed that the dynamic seepage pressure caused by the change of seepage field caused by the drop of reservoir water level affects the stability of slope. The buoyancy caused by the rise of reservoir water level, the pore water pressure produced by slope, and the weakening of strength parameters of sliding surface lead to the decrease of slope stability. The effect of water on the collapse of slope soil is seldom considered, and the influence may not be ignored.

The disintegration of soil, also known as wetting in geotechnical engineering, refers to the phenomenon of disintegration and collapse of soil after being immersed in water [11]. The disintegration of soil mass is due to the inconsistent thickening rate of the diffusion layer between particles after the soil is submerged in the water, which makes the repulsion force between particles exceed the suction force, and the soil mass collapses along the surface with the largest repulsion force [12]. The soil mass would collapse when encountering water, which would cause bank slope instability and endanger the engineering safety. According to the studies, soil disintegration did not occur in the process of water loss, but in the process of water absorption. The drying degree of soil mass had a great influence on the disintegration degree of soil mass [13]. Yamaguchi believed that the disintegration of soil mass was significantly affected by water content but less affected by temperature change [14]. Chen proposed that the main cause of soil mass disintegration was water absorption expansion of minerals, which resulted in compression of air and generated tensile stress. Then, the stress concentration resulted in soil mass collapse due to differential expansion [15]. Xu et al. found that the wettability of expansive soil after remolding was affected by water content and dry density [16]. The influence of water content and particle composition on the disintegration rate in the research on the disintegration characteristics of residual soil was analyzed by Cui and Yang. It was shown that the greater the water content, the faster the disintegration rate, the more the coarse particle content, and the faster the disintegration rate [17].

Therefore, the collapse of slope soil in water should be one of the important factors that affect the stability and cause damage of the reservoir bank slope. In this paper, test studies on the disintegration behavior of soil with different shapes and different water depths under the same volume condition will be conducted. The influence on the slope instability and failure will be explored. It is of great significance for the prevention and control of the geological hazards of the slope.

\section{Preparation of Soil Samples}

In this test, Xiashu clay was used as the soil sample. The basic physical indexes of the soil sample are shown in Table 1.

The soil sample was completely dried in an oven. After passing the $2 \mathrm{~mm}$ standard sieve, water was added the soil until the moisture content was $15 \%$. The samples were divided into cylinder with bottom diameter of $7 \mathrm{~cm}, 10 \mathrm{~cm}$, and $12 \mathrm{~cm}$, and quadrangular with bottom side length of $7 \mathrm{~cm}, 10 \mathrm{~cm}$, and $12 \mathrm{~cm}$, respectively, as shown in Figure 1. There were 6 kinds of samples in total. All samples with the same volume were prepared according to standard compaction, as shown in Table 2.

\section{Tests and Results}

3.1. Test Description. The test water tank was made of transparent acrylic to facilitate the observation of the sample disintegration process, as shown in Figure 2. A scale was set outside the side wall of the model box to observe the sample depth.

The water was added to the tank to $55 \mathrm{~cm}$ depth, and the prepared sample and the wire mesh tray were put into the water to the predetermined depth. The wire mesh tray was hung on the dynamometer hook through the four-angle sling. The depth of the sample from the water surface was $18 \mathrm{~cm}, 30 \mathrm{~cm}$, and $42 \mathrm{~cm}$, respectively. The data every half minute was recorded until the soil sample disintegrates completely. Repeat the above test steps until all tests were completed.

3.2. Test Results. The disintegration curve of the same volume samples in different water depth is shown in Figure 3. It can be seen from Figure 3 that the deeper the position was, the shorter the disintegration time was under the same initial conditions. The disintegration time of the sample is the longest at the water depth of $18 \mathrm{~cm}$ and the shortest at the water depth of $42 \mathrm{~mm}$. It also can be seen that, in the process of sample disintegration, the rate of sample disintegration in the early and later stages of the disintegration test was relatively small, and the rate of sample disintegration in the middle stage was relatively large.

The disintegration residual mass curve of the soil samples with the same volume and different shape at different water depth is shown in Figure 4. It can be seen from the curve in Figure 4 that the disintegration rate of quadrangular specimen was faster than that of cylinder specimen in the early stage of sample disintegration, but the disintegration rate of quadrangular specimen was slower than that of cylinder specimen in the later stage.

The disintegration residual mass curve of the cylinder soil samples with the same volume and different diameter at different water depth is shown in Figure 5. It can be seen from the curve in Figure 5 that the disintegration time of the thin cylinder soil sample is longer than that of the thick and short cylinder soil sample under the same volume and water 
TABLE 1: Basic physical indexes of soil sample.

\begin{tabular}{|c|c|c|c|c|c|c|}
\hline Name & Water content $w(\%)$ & Unit weight $\gamma\left(\mathrm{kN} / \mathrm{m}^{3}\right)$ & Specific gravity $G_{s}$ & Plastic limit $W_{P}(\%)$ & Liquid limit $W_{L}(\%)$ & Plasticity index $I_{P}$ \\
\hline Soil & 23.7 & 19.9 & 2.73 & 19.2 & 34.8 & 15.6 \\
\hline
\end{tabular}
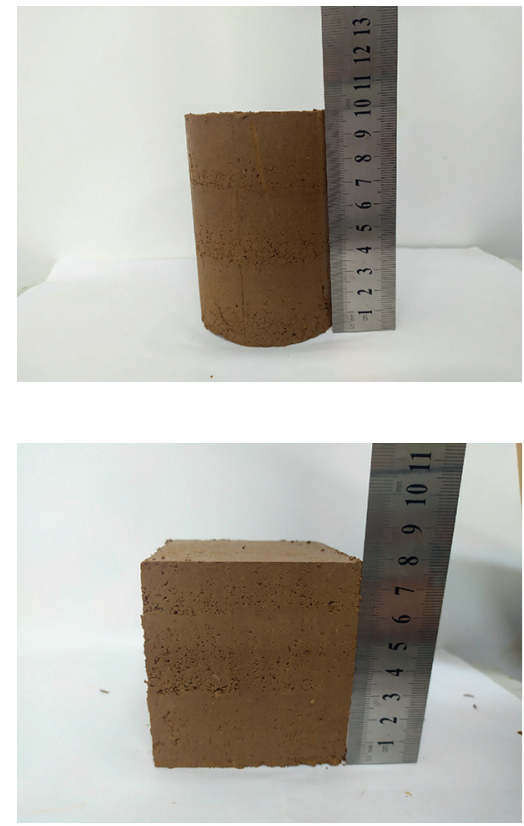

Figure 1: Soil samples, (a) cylinder samples, (b) quadrangular prism samples.

TABLE 2: The initial conditions of the soil samples.

\begin{tabular}{|c|c|c|c|c|c|}
\hline Shape & Diameter/side length $(\mathrm{cm})$ & Height $(\mathrm{cm})$ & Volume $\left(\mathrm{cm}^{3}\right)$ & Weight $(\mathrm{g})$ & Surface area $\left(\mathrm{cm}^{2}\right)$ \\
\hline \multirow{3}{*}{ Cylinder } & 7.0 & 10.2 & \multirow{3}{*}{392.7} & \multirow{3}{*}{805.0} & 301.3 \\
\hline & 10.0 & 5.0 & & & 314.2 \\
\hline & 12.0 & 3.5 & & & 358.1 \\
\hline \multirow{3}{*}{ Quadrangular prism } & 7.0 & 8.0 & \multirow{3}{*}{392.7} & \multirow{3}{*}{805.0} & 322.0 \\
\hline & 10.0 & 3.9 & & & 356.0 \\
\hline & 12.0 & 2.7 & & & 417.6 \\
\hline
\end{tabular}

depth condition. For the same volume of cylinder sample, the larger the diameter of the sample was, the larger the surface area was, the more the soil particles interact with water, and the easier the soil disintegration was.

The disintegration residual mass curve of the quadrangular prism soil samples with the same volume and different side length at different water depth is shown in Figure 6. It can be seen from the curve in Figure 6 that the disintegration time of the slender quadrangular prism soil sample was longer than that of the thick and short quadrangular prism soil sample under the same volume and water depth conditions. The final disintegration time of soil samples $10 \mathrm{~cm}$ and $12 \mathrm{~cm}$ side length was very close at the same depth of water. The disintegration law of the soil with quadrangular prism is consistent with that of the cylinder soil sample.

\section{Theoretical Analysis}

Clay particles have high hydrophilicity. A layer of water film is adsorbed on the surface of clay particles. The water film on the surface of the clay particles is composed of strong bond water, weak bond water, and free water in sequence, as shown in Figure 6. The formation of bound water film on the surface of clay particles can be roughly divided into two stages. The first stage is the formation process of the strong bound water layer with the strongest interaction with clay and the existence of chemical bond. The water molecules closest to the clay particles are firmly connected to the particle surface by coordination, electrostatic attraction, and hydrogen bond. The water molecules are oriented near the adsorption center to form a layer of adsorption layer (also known as stern layer), 


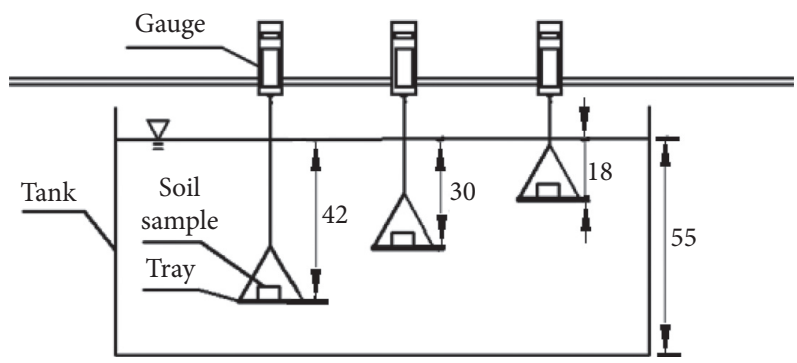

(a)

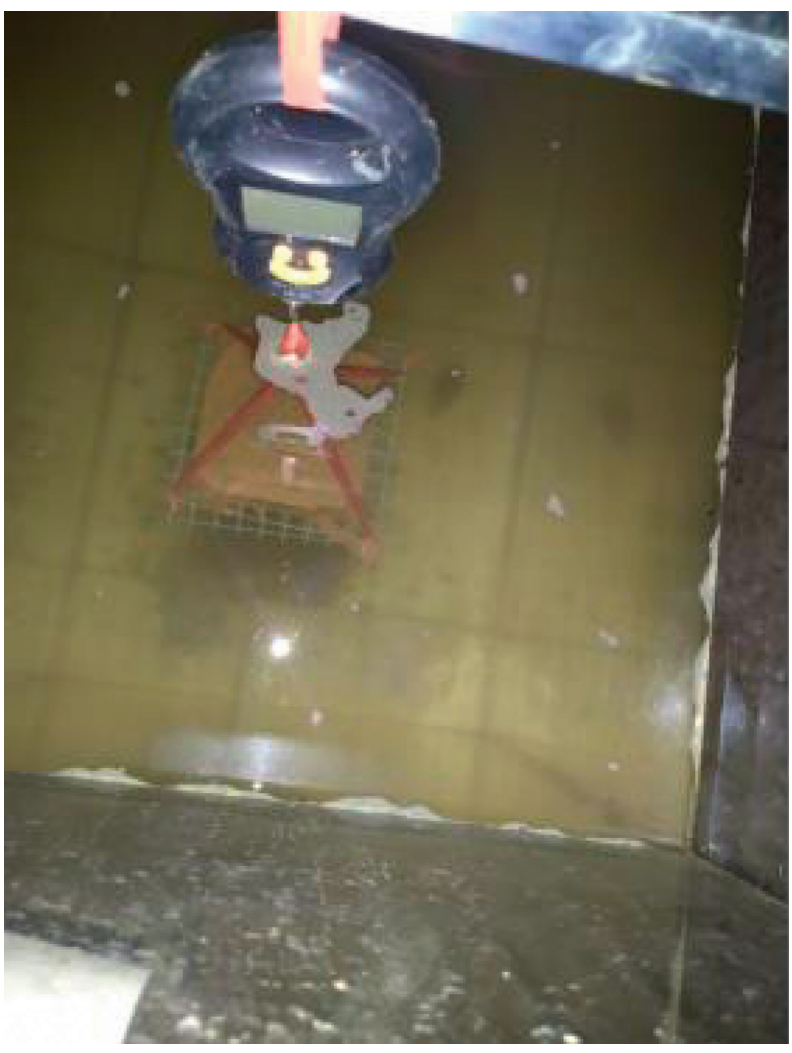

(b)

Figure 2: Model test system, (a) schematic diagram of test system (unit: $\mathrm{cm}$ ), (b) test picture.
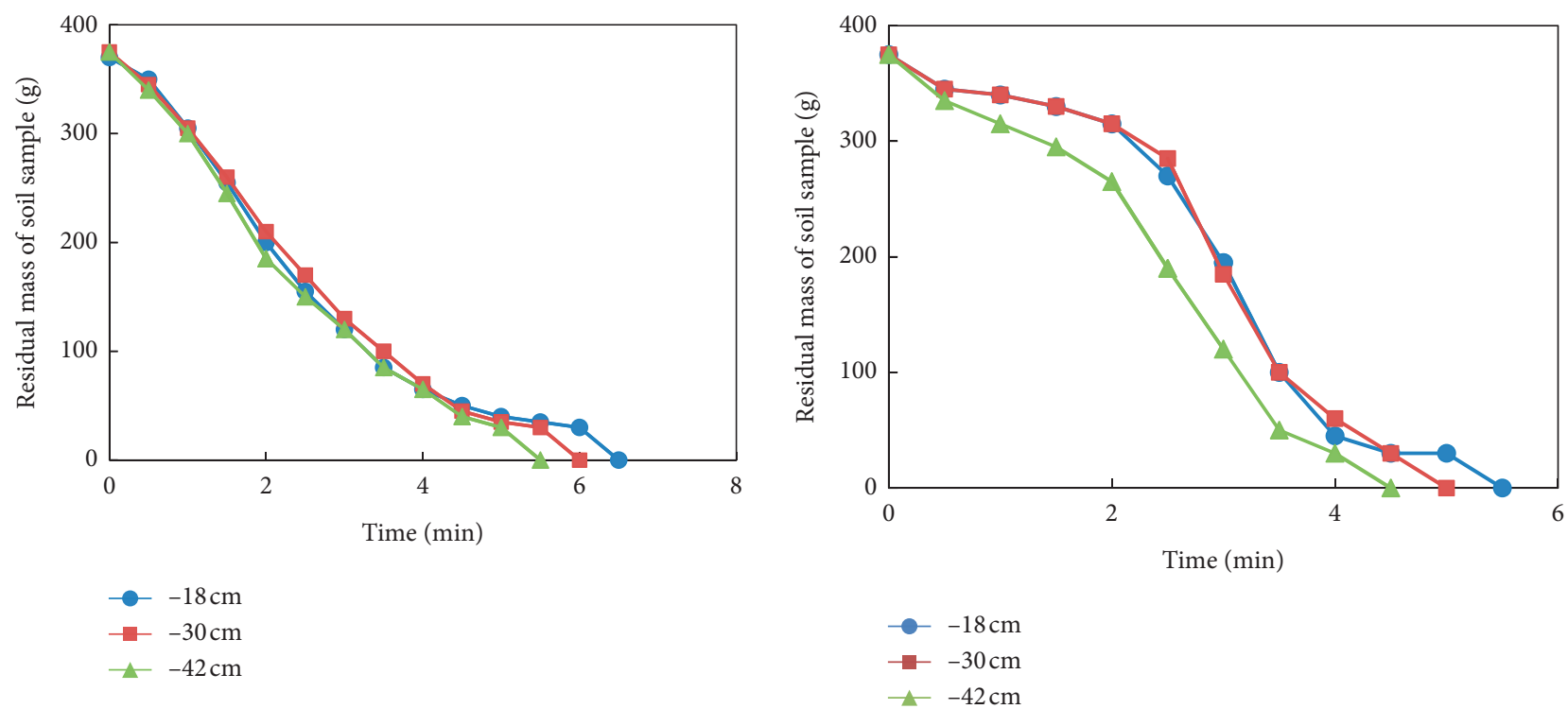

(a)

(b)

FIGURE 3: Continued. 

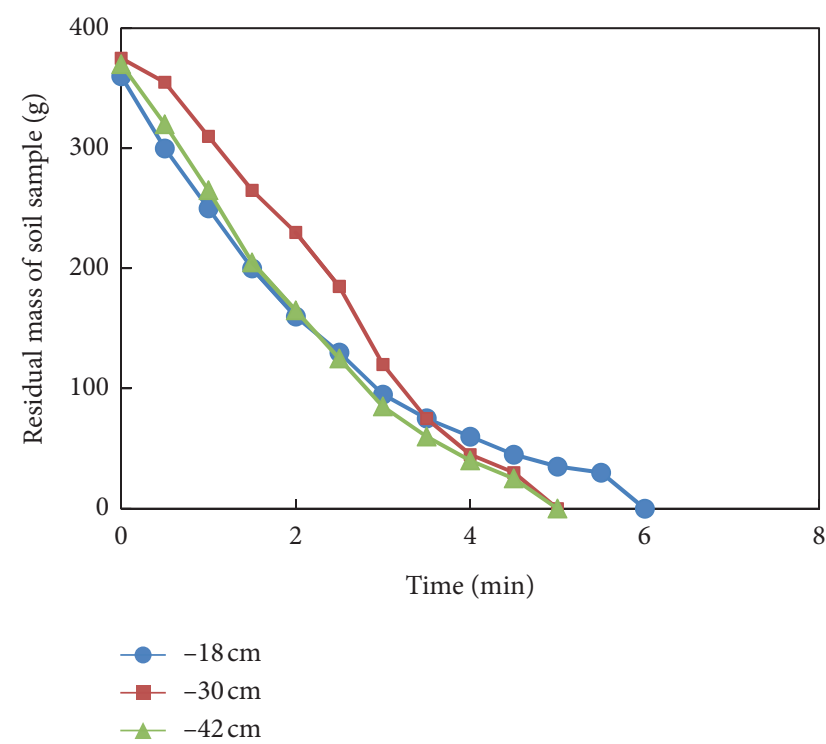

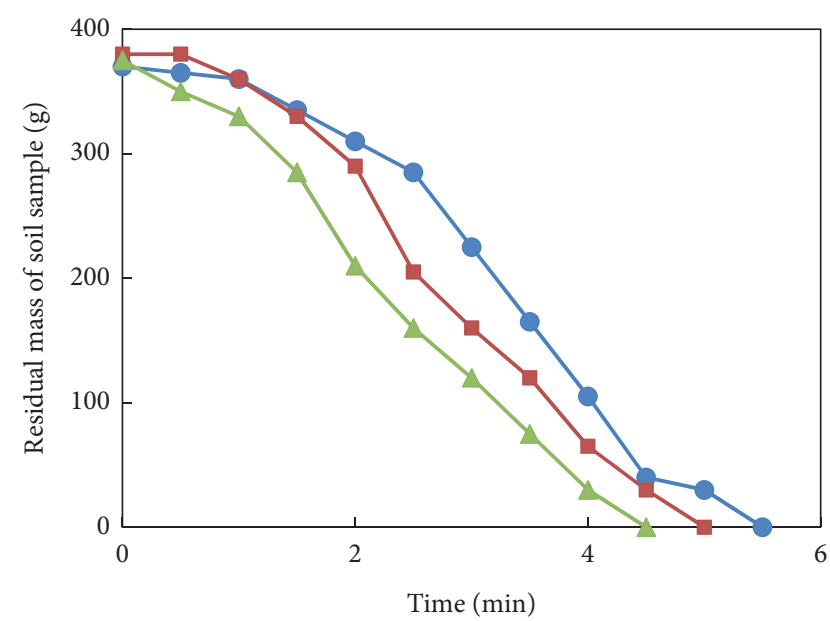

$--18 \mathrm{~cm}$
$--\quad-30 \mathrm{~cm}$
$--\quad-42 \mathrm{~cm}$

(c)

(d)

Figure 3: Disintegration curve of soil samples with the same volume at different water depth, (a) quadrangular prism of $10 \mathrm{~cm}$ section side length, (b) cylinder of $10 \mathrm{~cm}$ section diameter, (c) quadrangular prism of $12 \mathrm{~cm}$ section side length, (d) cylinder of $12 \mathrm{~cm}$ section diameter.

whose density is much higher than that of bulk solution. The mechanical property with great viscosity, elasticity, and shear strength is similar to that of solid. The stern layer is unable to transmit hydrostatic pressure, nonconductivity, and non-dissolving ability. The second stage is the formation process of weak interaction with the clay particles under a certain binding force. The water molecules slightly away from the surface of clay particles are oriented under the action of weak electrostatic attraction and Van der Waals force and form the weak bond water layer (also known as diffusive layer). The diffusive layer is a kind of viscous water film, which can move slowly from the thicker part to the thinner part; that is to say, the weakly bound water film can deform. The cations contained in the stern layer and diffusive layer are opposite to the negative charge potential on the surface of the soil particles, which form an anti-ionic layer. Then, a double electric layer is formed together with the negative charge on the surface of the soil particles, as shown in Figure 7.

Clay particles adsorb water molecules to form hydration membrane on the surface of particles, which increases the distance between clay lattice layers, produces expansion and dispersion, and leads to disintegration of soil. There are two stages of clay hydration expansion: surface hydration expansion and infiltration hydration expansion. The surface hydration expansion is caused by the surface hydration, which is the interaction of clay and water in a short distance. There are four water molecular layers between the clay layers, with a thickness of approximately $10 \AA$. At this time, the forces include Van der Waals force of interlayer molecules, electrostatic attraction between positive and negative charges of the layer, and hydration energy (adsorption energy) between water molecules and the layer, of which the hydration energy is the largest. The net energy of these three forces can reach thousands of atmospheric pressure when the first layer of water molecules enters. The expansion of infiltration and hydration is caused by the infiltrative force. When the distance between clay layers exceeds $10 \AA$, the surface adsorption energy no longer plays an important role. Then, the continuous expansion of clay is caused by osmotic pressure and double electric layer repulsion. As the water molecules enter the interlayer of clay crystal cells, the cations adsorbed on the surface of clay will be hydrated and diffused into the water, and the diffusion double electric layer is formed. As a result, the repulsion between the layers gradually plays a leading role, which leads to the further expansion of clay layer spacing. Secondly, there are many cations adsorbed between layers of clay, and the concentration of ions between layers is much higher than that inside the bulk solution [18]. Due to the existence of concentration difference, clay layer can be regarded as a permeable membrane. Under the action of osmotic pressure, water molecules will continue to enter into the clay layer, which causes further expansion of clay $[19,20]$. The membrane expansion caused by infiltration and hydration can make the spacing of clay layer reach $120 \AA$ A. When the hydration expansion of clay reaches the equilibrium distance (the interval between layers is about $120 \AA \hat{A}$ ), the crystal cells will separate and the soil will disintegrate under the action of shear force.

For the remolded dense clay, the soil particles have strong cementation ability. The cohesive force of the soil is large, and the water is not easy to penetrate into the clay. As the soil is immersed in the water, the diffusive layer between the soil particles thickens, and the bond water film thickens. The repulsion force between clay particles exceeds the suction force, the crystal cells separate, and the soil disintegrates. 

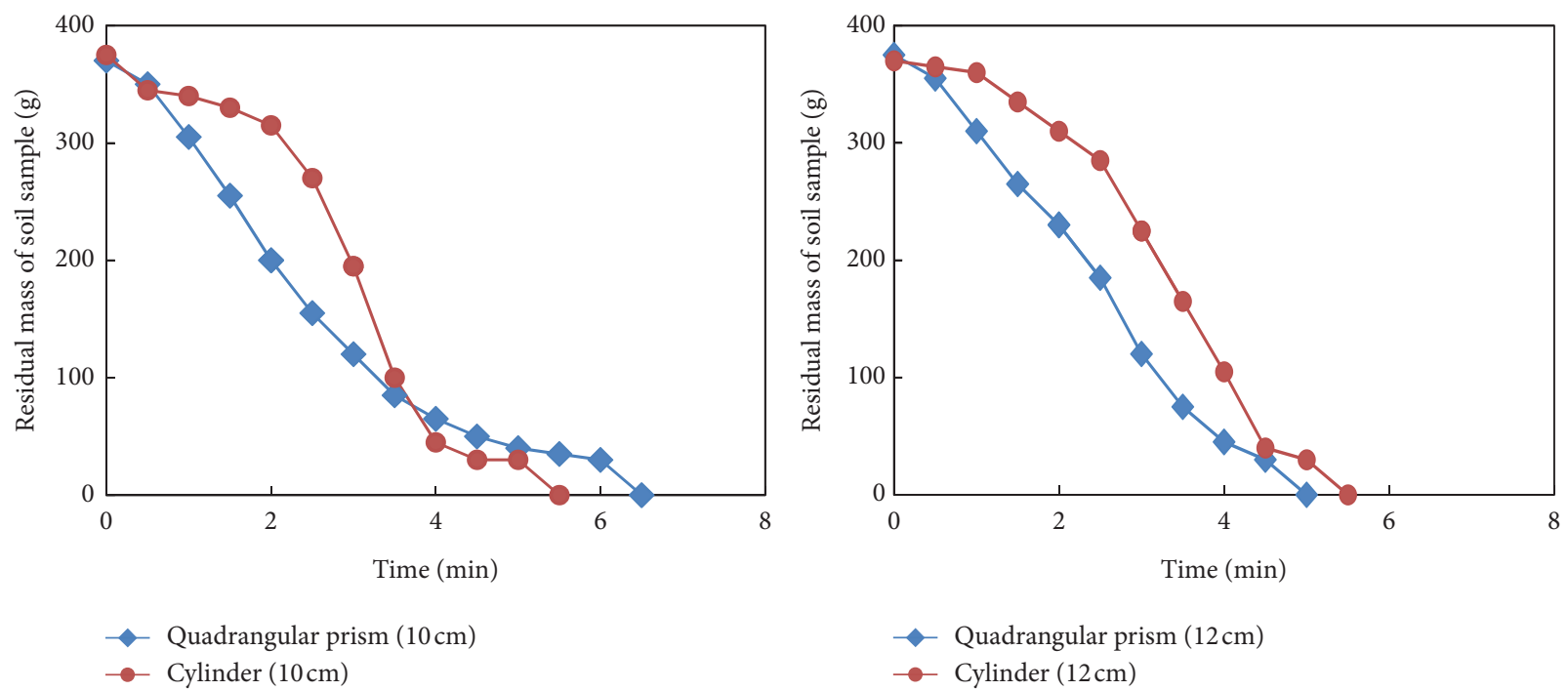

(a)
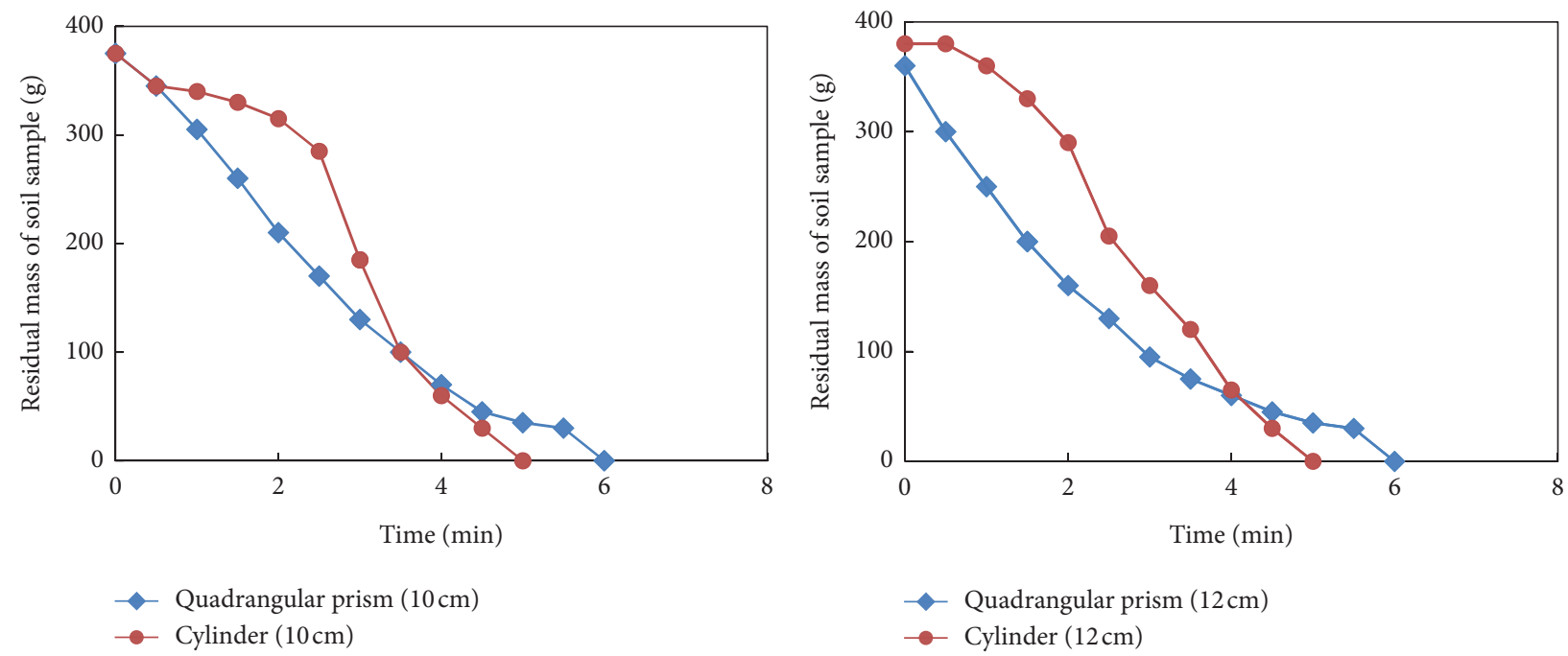

(b)
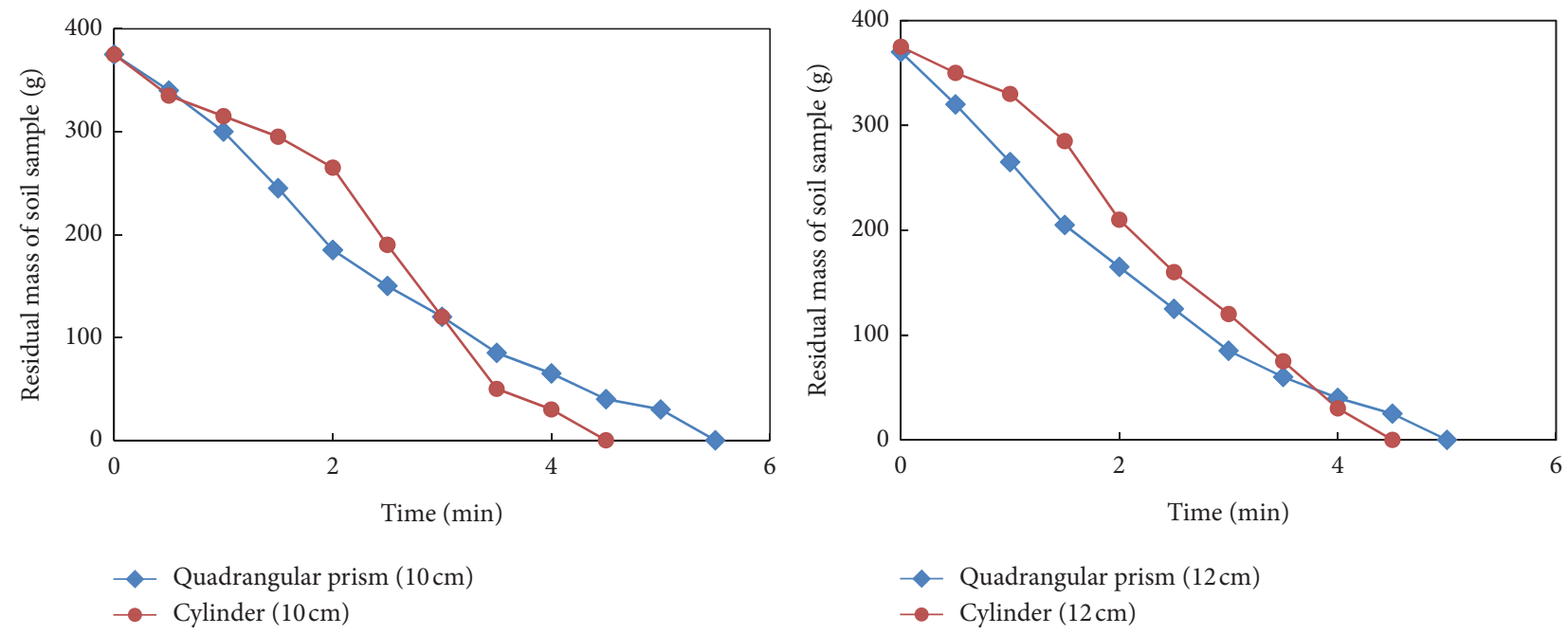

(c)

FIgURE 4: Disintegration curve of soil samples with the same volume and different shape, (a) $-18 \mathrm{~cm},(\mathrm{~b})-30 \mathrm{~cm},(\mathrm{c})-42 \mathrm{~cm}$. 

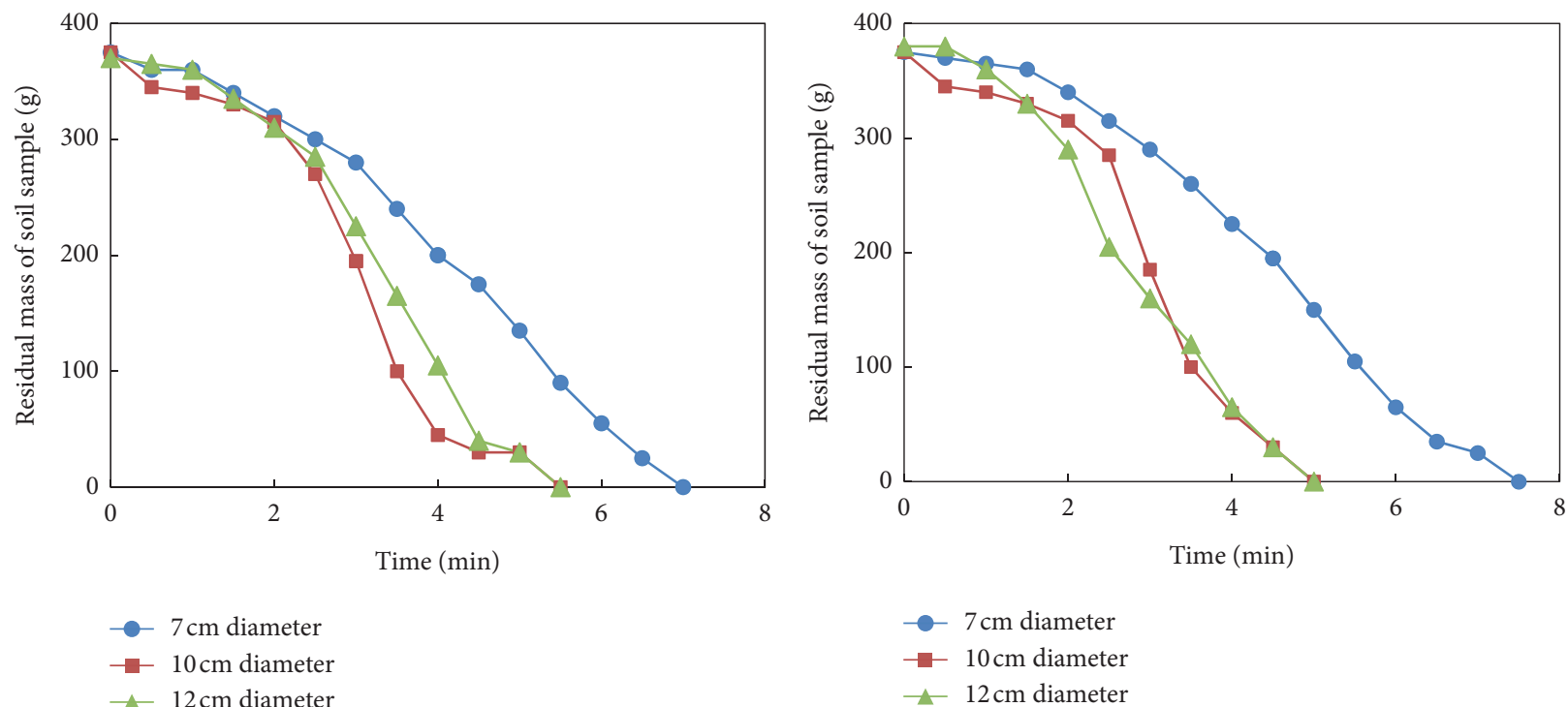

(a)

(b)

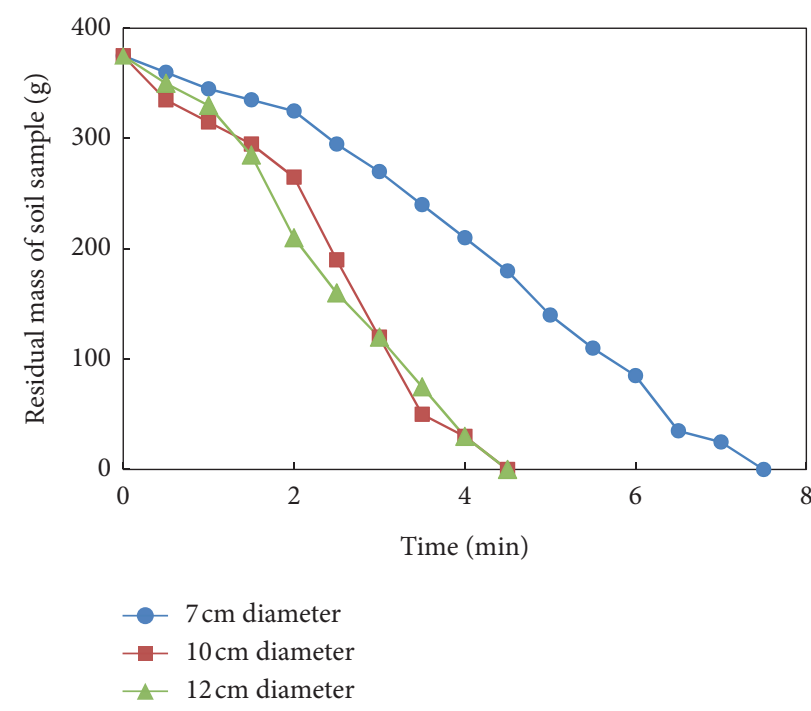

(c)

Figure 5: Disintegration curve of soil samples with the same volume and different diameter, (a) $-18 \mathrm{~cm},(\mathrm{~b})-30 \mathrm{~cm},(\mathrm{c})-42 \mathrm{~cm}$.
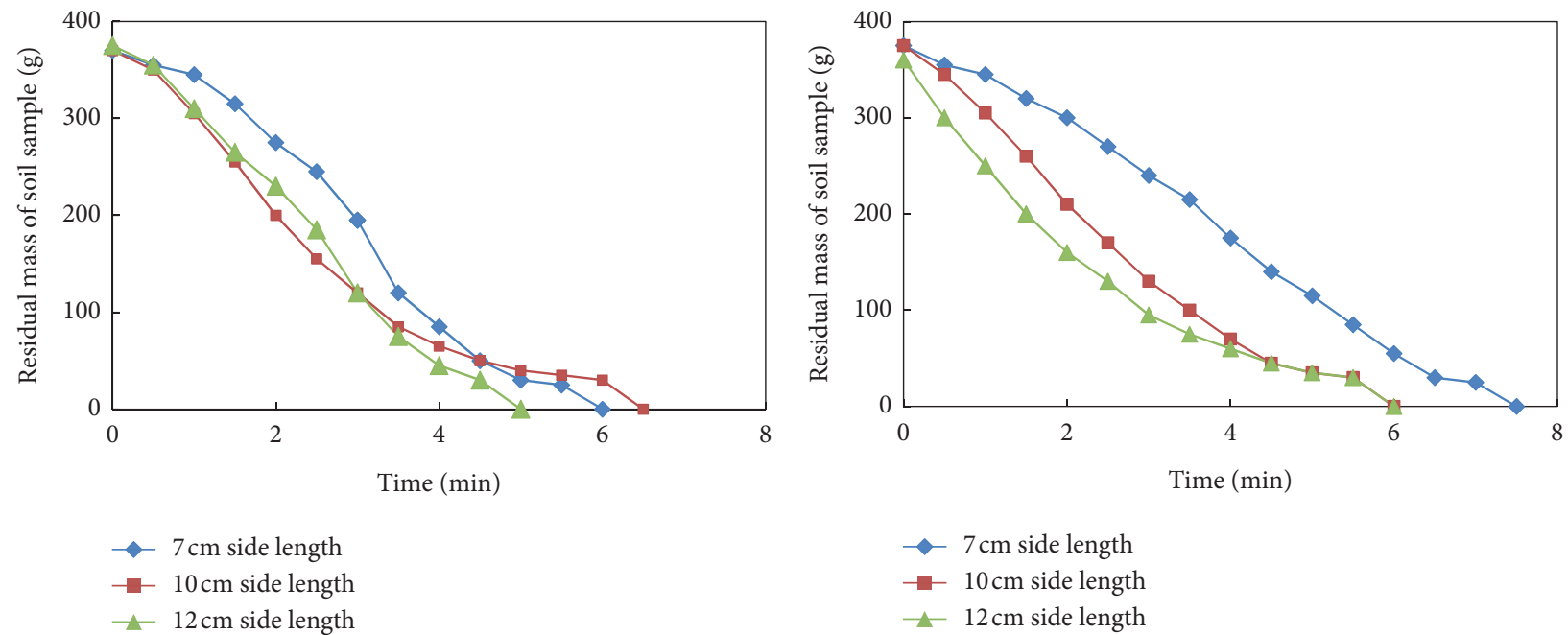

(a)

(b)

Figure 6: Continued. 


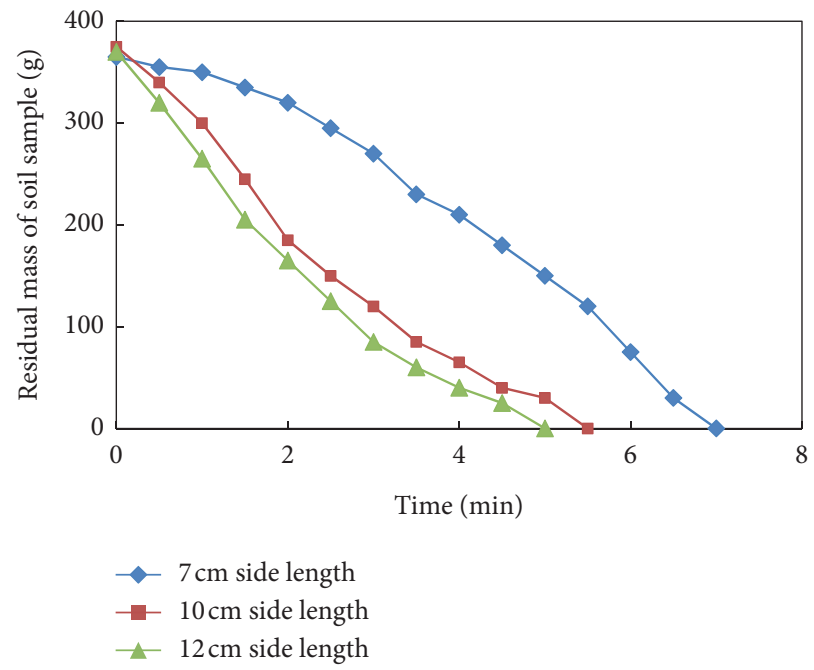

(c)

FIGURE 6: Disintegration curve of soil samples with the same volume and different side length, (a) $-18 \mathrm{~cm},(\mathrm{~b})-30 \mathrm{~cm}$, (c) $-42 \mathrm{~cm}$.

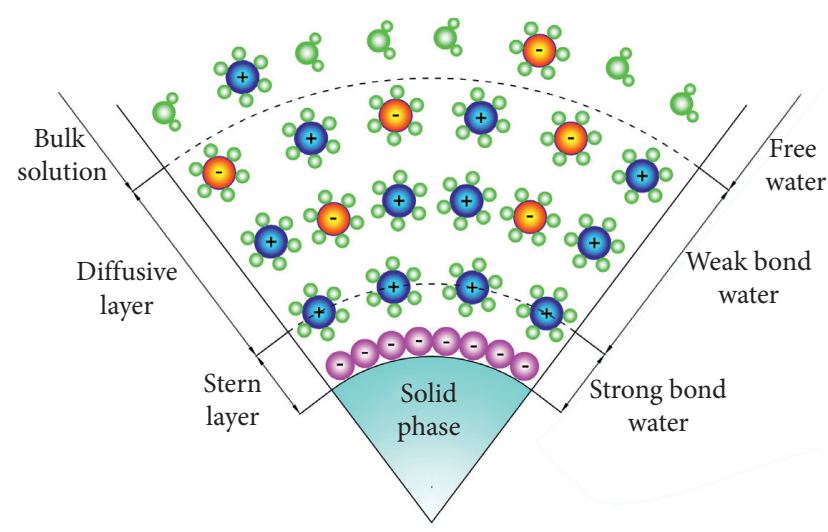

$\mathscr{\ell}_{0}^{\circ}$ Adsorbed cation

$\mathscr{C}_{0} 0$ Adsorbed anion

$\odot$ Surface charge

\& Water molecule

FIGURE 7: Schematic diagram of clay particle double electric layer model.

Before the soil is put into the water, the strong cohesive water in the soil occupies most of the channels in the soil pores, and the permeability is very low. With the increase of the water depth, the hydraulic gradient increases, the seepage pressure increases, the water molecules are easy to enter the clay layer, and the clay expansion, hydration, and disintegration are accelerated. It is shown that the deeper the water depth, the faster the soil disintegration. Therefore, water depth has an important influence on soil disintegration.

The specific surface area of the four prism samples is larger than that of the cylinder samples, and the clay particles combined with the water film at the corners are easy to absorb water and expand, resulting in soil disintegration. Therefore, the disintegration of the quadrangular specimen is faster than that of the cylinder specimen in the early stage into the water.

\section{Conclusion}

The collapse behavior of soil in water is related to the stability and failure of the bank slope. In this paper, a series of soil disintegration tests with different shapes and different depths under the same volume conditions are carried out. The conclusion is as follows:

(1) Water depth has an important influence on soil disintegration. The disintegration rate of the sample increases with the increase of water depth under the same initial conditions. For the reservoir bank slope, when the reservoir water level rises, the deeper the water depth of the soil slope below the water surface is, the greater the pore osmotic pressure is. The more the slope soil collapses, the less the pressure weight leads to the lower part of the slope, and the less the anti-sliding force of the slope soil is. At the same time, the shear strength of the soil decreases when the slope is immersed in water. The anti-sliding force is less than the sliding force, and the slope is unstable and collapsed when the water level rises under the conditions.

(2) The specific surface area of soil is one of the factors that affect soil disintegration. The larger the specific surface area of soil mass with the same volume and shape is, the faster the disintegration rate of soil is. With the same volume and different shape, the disintegration speed of quadrangular prisms in the early stage is faster than that of cylinders, but they are opposite in the later stage. 
(3) The disintegration of soil can be explained by the theory of soil particle surface combined with water film and soil double electric layer. The soil disintegration is mainly affected by the thickness of weak bound water film. In the expansion stage of infiltration and hydration, water molecules enter into the interlayer of clay crystal cells, which are separated and disintegrated by osmotic pressure and double electric layer repulsion.

\section{Data Availability}

The data used to support the findings of this study are available from the corresponding author upon request.

\section{Conflicts of Interest}

The authors declare that they have no conflicts of interest.

\section{Acknowledgments}

The work described in this article was supported by National Key Research and Development Program (2016YFC 0800201), National Natural Science Foundation of China (5120832), Natural Science Foundation of Jiangsu Province (BK20151071), Science and Technology Project of the Ministry of Housing and Urban-Rural Development of China (2019-K-136), and Science and Technology Project for Construction System in Jiangsu Province (2018ZD093).

\section{References}

[1] L. Zhong, "Enlightenments from the accident of vaiont landslide in Italy," Chinese Journal of Geological Hazard \& Control, vol. 9, no. 2, pp. 77-84, 1994.

[2] P. Paronuzzi, E. Rigo, and A. Bolla, "Influence of fillingdrawdown cycles of the Vajont reservoir on Mt. Toc slope stability," Geomorphology, vol. 191, pp. 75-93, 2013.

[3] X. P. Chen, "Overview of landslides due to reservoir impoundment based on shear strength properties of sliding zone soils," Advances in Science \& Technology of Water Resources, vol. 30, no. 3, pp. 77-83, 2010.

[4] X. Su, "Study on embankment stability of rising water level of a reservoir in Linyi city," in Proceedings of the 2017 International Conference on Algorithms, Methodology, Models and Applications in Emerging Technologies (ICAMMAET), Chennai, India, February 2017.

[5] A. I. Xiu-Feng, M. A. De-Qin, and SJ University, "The influence of water level falling in reservoir area on slope stability," Acta Geologica Sichuan, vol. 48, no. 2, pp. 155-159, 2015.

[6] X.-F. Yuan, H.-F. Deng, and J. Cai, "Stability analysis of talus slope near dam site under reservoir water level rise and fall condition," Water Resources \& Power, vol. 31, no. 9, pp. 135-137, 2013.

[7] X. Ru-Xue, X. Wan-Zhong, and S. Ding-Kang, "Overview of research on the influence of slope stability during reservoir water level rise and fall," Journal of Geological Hazards and Environment Preservation, vol. 30, no. 2, pp. 86-91, 2019.

[8] L. Han, Q. Rong, and S. Wu, "Study on seepage characteristics of reservoir bank slopes under water level fluctuation,"
Geotechnical Investigation \& Surveying, vol. 42, no. 7, pp. 26-30, 2014.

[9] B. Liu, J. Li, and Z. Wang, "Influence of seepage behavior of unsaturated soil on reservoir slope stability," Journal of Central South University, vol. 45, no. 2, pp. 515-520, 2014.

[10] X.-T. Xu and W.-B. Jian, "Experimental study on rainfall infiltration of slope under thrust at front end," Rock \& Soil Mechanics, vol. 38, no. 12, pp. 3547-3554, 2017.

[11] J. W. Gao, Y. U. Hong-Ming, and Y. Z. Qian, "Experimental study on disintegration characteristics of remolded loess," Journal of Yangtze River Scientific Research Institute, vol. 31, no. 10, pp. 146-150, 2014.

[12] Z. Luo, F. H. Gong, M. J. Song, and S. W. Zhao, "Advances in research on rock and soil engineering disaster," Journal of Hunan Institute of Engineering, vol. 15, no. 1, pp. 87-91, 2005.

[13] D. Zhang, A. Chen, and G. Liu, "Laboratory investigation of disintegration characteristics of purple mudstone under different hydrothermal conditions," Journal of Mountain Science, vol. 9, no. 1, pp. 127-136, 2012.

[14] H. Yamaguchi, K. Yoshida, and I. Kuroshima, Slaking and Shear Properties of Mudstone, International Society for Rock Mechanics and Rock Engineering, Lisbon, Portugal, 1988.

[15] X. P. Chen, P. Y. Qian, and Z. S. Liang, "Study on slaking stability of excavated high slope of argillaceous soft rock," Chinese Jounal of Geotechnical Engineering, vol. 25, no. 5, pp. 543-547, 2003.

[16] L. L. Xu, X. M. Qu, and L. J. Liu, "Experimental study on expansion characteristics, frost heaving characteristics of EPS beads improved expansive soils," Advanced Materials Research, vol. 742, pp. 80-84, 2013.

[17] K. Cui and Y. Yang, "Experimental study on engineering characteristics of basalt residual soil on high slope," Applied Mechanics and Materials, vol. 580-583, pp. 460-463, 2014.

[18] Q. Tang, W. Liu, Z. Li, Y. Wang, and X. Tang, "Removal of aqueous $\mathrm{Cu}(\mathrm{II})$ with natural kaolin: kinetics and equilibrium studies," Environmental Engineering and Management Journal, vol. 17, no. 2, pp. 467-476, 2018.

[19] Q. Tang, T. Katsumi, T. Inui, and Z. Li, "Membrane behavior of bentonite-amended compacted clay towards $\mathrm{Zn}(\mathrm{II})$ and $\mathrm{Pb}$ (II)," Membrane Water Treatment, vol. 6, no. 5, pp. 393-409, 2015.

[20] Q. Tang, T. Katsumi, T. Inui, A. Takai, and Z. Li, "Influence of compaction degree on membrane behavior of compacted clay amended with bentonite," in Proceedings of the Geo-Congress 2014 Technical Papers, Atlanta, Georgia, February 2014. 